\title{
Task-Driven: Does It Effect on Students' Mathematical Reasoning Skills?
}

\author{
E. Elvis Napitupulu \\ Mathematics Department, \\ Universitas Negeri Medan, Indonesia \\ Ani Minarni \\ Mathematics Department, \\ Universitas Negeri Medan, Indonesia
}

\begin{abstract}
One of the most difficult task to handle in part of students in learning mathematics is mathematical reasoning. Due to the deficiency, this study attempted to help the students grasp the skill by disseminating a set of learning materials, which had been developed in the previous study and fulfilled the validity, practicality, and effectivity criteria. The learning materials consisted of student book (SB) and student worksheet (SW). The developing of the two devices (SB and SW) intended to improve the students mathematical reasoning skill (MRS). At amount of 135 students from four public senior high school participated in the study. The study used pre-test and post-test on MRS to find the improvement of MRS and scale of perception to reveal the students perception on the SB and SW. The findings showed the students MRS improved albeit in low category and the students had positive response to either the SB or SW.
\end{abstract}

Keywords: task-driven, effect, students, mathematical reasoning skills

\section{INTRODUCTION}

Mathematics is a discipline of knowledge with abstract objects. From the beginning, when the children enter their classrooms and start learning, they have to face numbers, which abstract concept with abstract symbol. The upper level they engage the more abstract concept they encounter. Representation then becomes a powerful and helpful tool to learning and understanding mathematical objects. Yet, to represent an abstract object is not an easy task. That is why one should think hard while learning mathematics. In its turn, the children start seeing and perceiving mathematics as a difficult and terrible subject matter.

Thinking is a main and primary tool or work in learning mathematics. Actually, it is natural for thinking is the only one given to human being and not to other creatures. The existence of human being is inherent with his ability to think, as René Descartes asserted a long time ago. In learning or doing mathematics, one ought to draw conclusion, even at each step. To be sure or valid, the conclusion should be drawn deductively. In the process of drawing the conclusion, one should be able to see how things interrelate, looks for pattern emerged and makes effort to generalize or logical conclusion, and makes conjecture and simultaneously its proof [1] and [2]. All of the work constitute mathematical reasoning.

Learning mathematics is really doing mathematics and every step of doing mathematics needs reasoning. Therefore, learning mathematics is identic with reasoning mathematically. Concerning this, Lithner [3] emphasizes that reasoning is the foundation of mathematics (p. 165). Moreover, Norqvist [4] notes the necessity for students to engage in more cognitively 
demanding activities than just train to imitate the demonstrated solutions given by their teachers. To become a successful mathematics learning, a child should be engaged from the beginning in an environment in which reasoning is a habit. If the children are to learn mathematics, it is a must to ask them not only imitate the ways or the methods their teachers demonstrate but the most important one is also to give them tasks which ask to reason such that the conclusion they draw is valid. It should a habit that every mathematics conclusion they draw must be based on mathematical reasoning. Doing so, they become productive citizens by means that they always take responsible to what they think and to what they do.

It is therefore evident that the students must grasp the skill to reason mathematically. Just like embracing other skill, the teachers could lead their students to grasp the skill by asking them solving problems, which need load a lot of reasoning. The teachers could and should nurture such that his students grow in an environment which rich with various mathematical reasoning. In this case, Lithner [5] asserted that students should engage themselves in activities in which they must struggle to embrace important mathematics competencies. However, unfortunately it seems that it is not the case happened. The previous study revealed most mathematics teachers in Indonesia conduct the lessons by asking the students imitate the method they used to answer some exercises [6], [7], and [8]. They rarely engaged their students to think mathematically by means of reasoning to answer important questions or to investigate why a certain method run well to handle some problems and not for other, for example. Another fact encountered that the students lacks mathematical reasoning skills (MRS) at all level [9].

To overcome the two main problem, this study took place. It aimed at defined, designed, developed, and disseminated a set of learning materials, which intended to improve the students MRS at upper secondary level. The learning materials contained among others tasks, which demand and ask the students to struggle making use their previous knowledge and experiences solving problems in a meaningful context. Concerning this, Lithner [5] emphasize children should develop reasoning skills by engaging actively in corresponding challenging learning processes. This paper reported the second part of the study, i.e. disseminating the learning devices that had been produced in the first year of the study. In the first year of the study, the researchers had developed the learning materials and had been proved valid, practice, and effective in the framework of Nieveen and Folmer [10]. In addition, the intervention intended to reveal the students perception on the learning materials and the way they engage in the teaching and learning process.

Not long ago, Bergqvist \& Lithner [11] conducted a study to find out what opportunities students have to learn various kinds of mathematical reasoning from their teachers' tasksolving presentations. However, it is not concern with what learning actually takes place. Recently, Lithner [5] proposed a framework for designing mathematical tasks to improve imitative and creative reasoning. The study presented a basis theoretically for analyzing causal effect of task or teaching design on learning outcomes. Nevertheless, very little study which reported how the process of teaching and learning can improve the students MRS. In this direction, Bieda[12] asserted that research has not examined students' opportunities to develop deductive reasoning and to learn skills for evaluating the validity of others' mathematical arguments. In this case, the study aimed at exploring the effect of the teachinglearning processes, which implemented learning materials developed to enhance the students MRS in general. It is really believed that the intervention would give a strong effect on the students side for they are being interested following the lessons and think that the learning materials is challenging and enforce them to think hardly. 


\section{METHODOLOGY}

The study was developmental in nature. It followed the 4-D Model from Thiagarajan, et al. [13]. The first three $\mathrm{D}$ had been completed in the first year of the study. The second year was dedicated for disseminating the learning materials produced in the first year to see its effect on a wider subject. The learning materials developed in the first year consists of Teacher's Handbook, Students Guide Book, which contains Students Worksheet (SW), and the instrument, pre-test and post-test, to measure students MRS. The study took topic in trigonometry for tenth grade beginning with trigonometric comparison at various quadrants, trigonometric identities, and sine and cosine rules. After administering pre-test, the teachers delivered the subject matter during six or seven courses, ended by post-test and interview. Each course took duration ninety minutes, while either pre-test or post-test took eighty.

The subject of the study was tenth grade students, at amount of 135 , from four school with Aranked. Each school contributed one classroom, which averagely contained thirty-four students. The study was conducted in the second semester of 2017/2018 Academic Year. Before the intervention took place, the subject rarely engaged in a cooperative/collaborative setting while learning mathematics. Their teachers usually use the book the government provided as a source, explain the materials followed by giving routine examples, and then asked the students to do some similar exercises, either in the classroom or as a homework. They almost never worked solving problems, which demanded various mathematical reasoning.

There existed two main kinds of instrument used in the study. First, the test consisted of pre and post to measure the students MRS. Second, questionnaire to obtain the students perception on the learning materials and the method the lessons delivered. An interview was run to reveal the path of thinking the students took while solving a certain problem. Each test consisted of four problems and the questionnaire contained fourteen items. The four problems measure four indicators, i.e. (1) Draw logical conclusion; (2) Use relationship of pattern to analyse situation, to make analogy, or to generalize; (3) Give explanation on model, fact, properties, relationship, or pattern exists; and (4) Make a conjecture and its proof [9]. Both instruments had fulfilled the criteria valid, practice, and effective from the previous study [7]. Problem number 1 measures indicator (1) and (2); Problem number 2 measures indicator (1), (2), and (4); Problem number 3 measures indicator (1) and (4); Problem number 4 measures indicator (1), (2), and (3). Maximum score for each problem number 1 up to 3 was ten, while for problem number 4 was twenty. The scores the students achieved then converted to 100scale. The students perception was dichotomized between agree and not agree.

The researchers administered pre-test before implementing the intervention. The pre-test consisted of four problems measured the four indicators mentioned above. The problems in the pre-test covered topic on function and introduction to trigonometry. After completing the pre-test, the regular teachers at the four schools then conducted the lessons using the learning materials. The main activities of the course was solving problems. Implementing problembased learning, the teachers directed and guided their students solved the problems provided in the students worksheet (SW). The students worked cooperatively in-group of five or six. There existed nine, six, and five problems consecutively in SW 1, 2, and 3. The entire problems in the SW pursued the four indicators.

The teachers needed six to seven courses to run the entire SW. The course took duration ninety minutes each. Although paying seven courses, not all of the groups be able solving the entire problems in the classrooms. During running the courses, the teachers continuously help the students either in-group or classically to solve certain problems in the SW, especially at the 
beginning. The aids the teachers gave in form of scaffolding or reminding some concepts related such that the students were not in stuck. The students remained played role as problem solver. At the end of the intervention, the researchers and the teachers administered post-test and followed by a limited interview on selected students based on their answer sheets on certain problem.

The study intended to intervene the process of teaching and learning by implementing learning materials had been developed previously. The intervention took place in the frame of enhancing the students MRS and inhibiting habit of problem solving. The existence of students MRS enhancement was seen using Hake's gain [14], while students perception on the learning materials and the process of teaching and learning was presented descriptively, and students performance on MRS was analyzed qualitatively.

\section{Students' MRS}

\section{RESULT}

Students average score on MRS either from pre or post is presented in Table 1 [15]. The data shows, overall, the intervention effects on the students MRS, albeit the enhancement is low. However, the students enhancement on MRS of SHS 1 and SHS 2 outperformed the other two. Especially, those from SHS 1, they performed exceptional achievement. Such post-test score is high for high order thinking skill. On the contrary, the students in SHS 4 did not get any advantage of the intervention. Their pre-test and post-test score did not differ significantly. This result also reveal that the intervention did not have equal affect to all of the students. Moreover, the students pre-test from SHS 2 was worse than those from SHS 3 and 4, but their post-test was better. The worst performance goes to SHS 4.

During the lessons, the students worked in-group on three SW. The first SW contained nine problems on trigonometric comparison in various quadrants and its applications. The students from SHS 1 were able completing the tasks as well as those from SHS 3. On the contrary, those from SHS 2 and 4 failed on certain tasks. For example, Figure 1 showed the work of one group in from SHS 2. The task asks to express $\sin 50^{\circ}$ and $\tan 40^{\circ}$ in $k$ if given $\sin 130^{\circ}=k$. Their work correct for the first part but wrong for the second. They were able to using the relationship of sine between the first and the second quadrant, but they failed to combine the expression of tangent in sine and cosine and the expression of sine in the first quadrant for complementary angle. The problem they fell in was the difficulty to connect what they have with the previous related knowledge.

Table 1. Students' MRS enhancement based on school.

\begin{tabular}{|l|l|l|l|l|}
\hline & Pre-test & Post-test & N-Gain & Qualification \\
\hline SHS 1 & 47.4 & 84.9 & 0.7 & Medium \\
\hline SHS 2 & 10.9 & 47.3 & 0.4 & Medium \\
\hline SHS 3 & 32.6 & 38.7 & 0.1 & Low \\
\hline SHS 4 & 26,7 & 27 & 0 & Low \\
\hline Overall & 29.3 & 49 & 0.28 & Low \\
\hline
\end{tabular}

SHS: Senior High School

Contrary to the above fact, the entire students from SHS 1 and almost all those from SHS 2 successfully completed the task even for the most difficult one from SW 1, problem no. 9 shown in Figure 2. The problem asks to find the length of $B D, A D, F B, A E, D E \sin 75^{\circ}, \cos 75^{\circ}$, and tan $75^{\circ}$, if given length of $B C=1$. Figure $3 \mathrm{a}$ and $3 \mathrm{~b}$ exhibit their work on that problem. They showed their understanding and mathematical reasoning on that figure. For example, in Fig. $3 \mathrm{~b}$, they directly note the length of $A C=1$ and $A B=\sqrt{2}$ using the given information. 


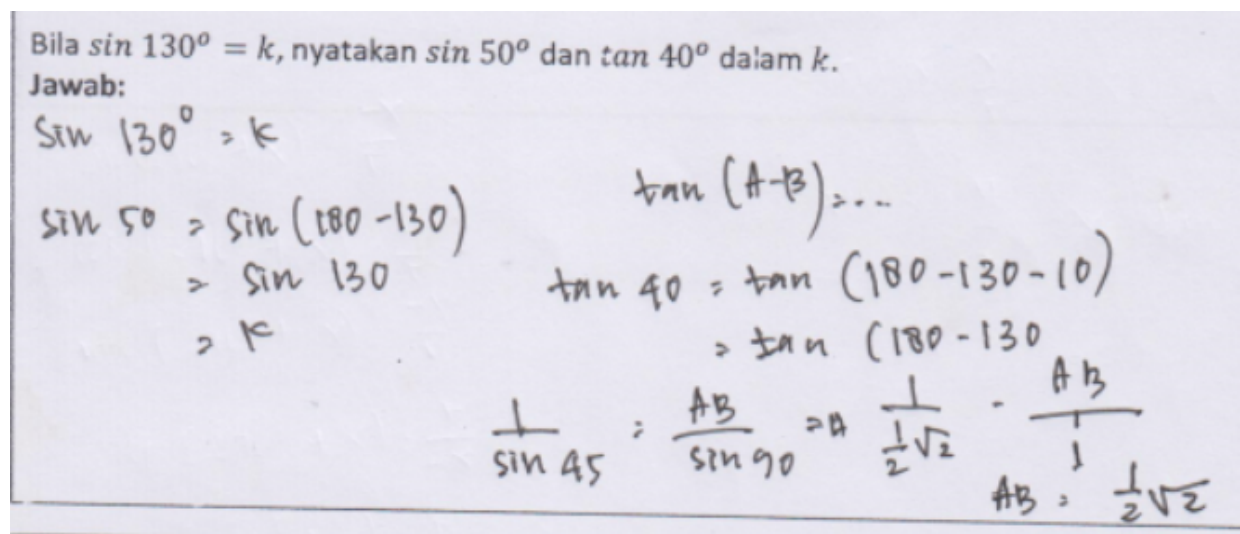

Figure 1. Students work on one problem of SW 1

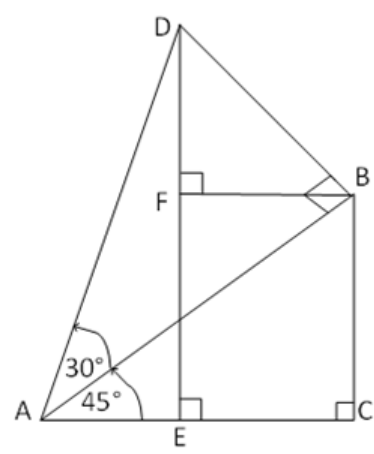

Figure 2. Problem No. 9

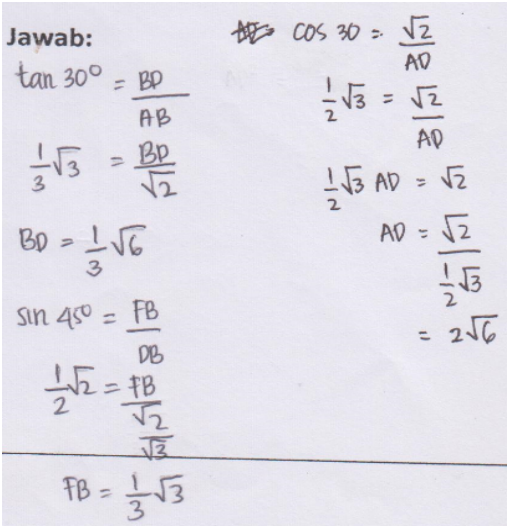

Figure 3a. Students answer on Problem No. 9

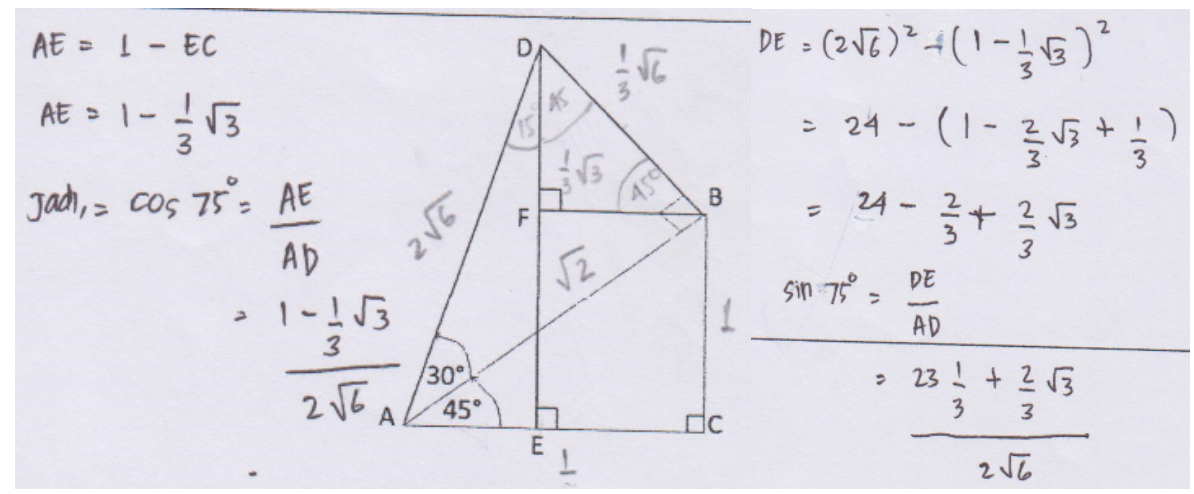

Figure 3b. Students answer on Problem No. 9

Similar result obtained for SW 2. Most of the students failed to comprehend what their task asks. For example, problem number 4 from SW 2 asks to show if $\frac{1+\sin x}{\cos x}=k$, then $\frac{1-\sin x}{\cos x}=\frac{1}{k}$. Actually, to complete the task, they should manipulate the given to get the algebraic form demanded. Instead of doing that, they only verified an identity, which actually should be proved (Fig. 4). On the contrary, the students from SHS 1 were able to solve the most difficult task from SW 3, although the others were not. The task asks to find $\sin x+\cos x$ in $a$ if $\sin x+\sin$ $y=a$ and $\cos x+\cos y=a$. the students from SHS 2 for example just wrote something speculative or draw a conclusion without reason (Fig. 5). 


$$
\begin{aligned}
\text { lawab: } & \frac{1+\sin x}{\cos x}=k \cdot \frac{k}{1}=\frac{\cos x}{1+\sin x} \\
k & =k \\
\frac{1+\sin x}{\cos x} & =\frac{\cos x}{1-\sin x} \\
(1+\sin x) & (1-\sin x)=\cos x \cos x \\
1-\sin x+\sin x-\sin ^{2} x & =\cos ^{2} x \\
1-\sin ^{2} x & =\cos ^{2} x
\end{aligned}
$$

Figure 4. Students answer on Problem No. 4

$$
\begin{aligned}
& =\sin x+\sin y+\cos x+\cos y=2 a . \\
& t(\sin x+\cos x)+(\sin y+\cos y)=2 a . \\
& =\left(\frac{1}{2} a+\frac{1}{2} a\right)+\left(\frac{1}{2} a+\frac{1}{2} a\right)=2 a . \\
& a+a=2 a . \\
& \text { Maka: } \sin x+\cos x=a .
\end{aligned}
$$

Figure 5. Students answer on Problem from SW 3

The entire group in the classroom from SHS 1 were capable to solve the entire problems in all SW. Their success to solve the entire problems represented in their performance on the posttest. Most of them successfully completed all the problems of the post-test. On the opposite side, the students from SHS 4 and some from SHS 3 hardly faced the problems in the SW, which effect to their bad performance on the post-test.

For example, problem number 1 of the post-test asks to find $\sec x+\tan x$ if given $\sec x-\tan x=$ 2. Two different students form SHS 1 answered it in a totally different path (Fig. 6). Instead of multiply the known by its conjugate, which is asked, the first sheet began with square the given (a). While the second sheet (b) began with an identity to get the term asked. Such a creative thinking. The researchers then took an interview with the student wrote the first sheet, which presented below.

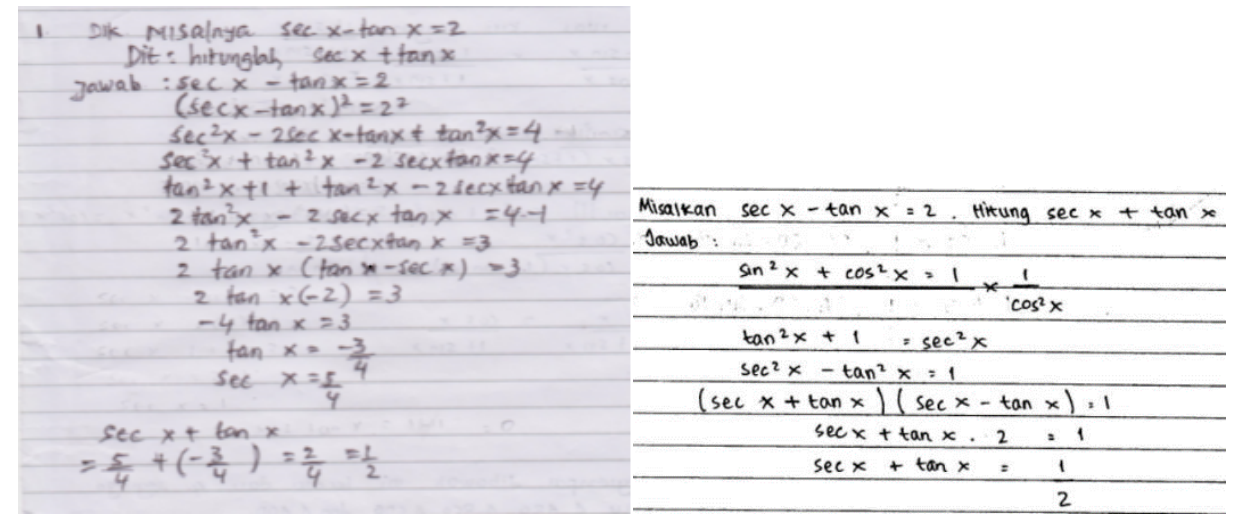

Figure 6. Two student's work from SHS 1 on problem 1 of the Post-test

Researcher (R): Why did you square the known?

Student (S): In SW, I met a problem solved similarly. Therefore, I tried to this one.

R: But, the one in SW was not similar to this problem.

S: Exactly. Nevertheless, I just tried it. I did not have any other idea.

R: Okay, at the end you only got $\tan x$.

S: Wright. However, I could proceed finding the $\sec x$, after.

R: How did you do it? We could not see it on the sheet.

S: I computed it in my head.

R: After completing the task, did you get in mind, for example, to multiply the known with what to find?

S: No. I will try it.

\section{Students' perception on SB and SW}

On the other part, Table 2 exhibit the students perception on the student book (SB) and SW which used during the teaching and learning process. The students responded positively to the entire item. Exception only goes to item number 2. They thought the SB lacks of explanation for it only provided important concept and principles briefly. From the beginning, the researchers 
did not intend to make it as a source book for they have in hand one and used daily. Consequently, the SB does not contain any examples, which usually follow the concept or principles presented. That is why they perceived the SB difficult to pursuit caused of discontinuities. Last, they considered the language used either in the SB or SW difficult to understand. It is more likely that they are accustomed to reading and seeing routine exercises. Overall, on the students perception, the SB and the SW have fulfilled and facilitated their need in developing their MRS.

Table 2. Students' perception on the SB and the SW

\begin{tabular}{|c|l|c|c|}
\hline No & \multicolumn{1}{|c|}{ Statement } & Agree & Not agree \\
\hline 1 & SB help me comprehend the materials more & 108 & 11 \\
\hline 2 & SB lacks of explanation & 66 & 29 \\
\hline 3 & SB endorse me relating knowledge & 90 & 11 \\
\hline 4 & Difficult to pursuit SB caused of discontinuities & 45 & 34 \\
\hline 5 & SB is attracting and interesting & 74 & 33 \\
\hline 6 & SB could not be used learning resource & 16 & 95 \\
\hline 7 & Problems in SW are difficult & 77 & 24 \\
\hline 8 & We could solve problems in SW with help & 118 & 9 \\
\hline 9 & Problems in SW endorse learning more actively & 80 & 14 \\
\hline 10 & Problems in SW are nonsense & 8 & 94 \\
\hline 11 & Solving problems in SW enhance mathematical skills & 79 & 18 \\
\hline 12 & I am able solving problems in SW alone & 11 & 76 \\
\hline 13 & Tasks in SW are not interesting to discuss & 22 & 79 \\
\hline 14 & SW's language is difficult to understand & 55 & 51 \\
\hline
\end{tabular}

\section{DISCUSSION}

\section{Students' MRS}

The result of the study showed that the intervention succeeded achieving its goal. The students MRS improved, albeit overall, categorized low. Evaluating the students work on the post-test, it is readily seen that they got advantage of the experiences solving the problems in the SW. In some cases, they were able to transfer the knowledge and skills they grasped while solving the problems in the SW in-group to solving the problems in the post-test. The evidence occurred especially in the first two classrooms, that is SHS 1 and 2. This result is in-line with Burns et al [16] finding that working collaboratively foster greater levels of engagement. In Vygotsky's perspective, the students were capable activating their zone of proximal development through working together with advanced peers or expert adults. However, although the teacher in SHS 3 made serious effort on helping her students to solve all of the problems in the SW, many of them were not able completing the tasks. On the contrary, the teacher in SHS 4 rarely helped her students and almost never fostering and encouraging the students solving the problems in the SW. This resulted on their failure solving the problems in the post-test.

From the beginning, it is well perceived difficult to catering students MRS. First, due to the habit of the teachers, which mostly conduct the lessons traditionally. Second, the students are accustomed to doing routine exercises. Consequently, many students were resistant to a different model of teaching and learning process, such one conducted in this study. The purpose of the study was to improve students MRS by means of implementing learning materials developed in the previous study. The intervention used problem-based learning to deliver the lessons. İt is absolutely therefore important the role and good will of the teachers to create a supporting environment for the students learning and grasping high order thinking such as mathematical reasoning. The teacher should pay much attention on the progress or failure of his students engaging in the activities of thinking mathematically. He should be aware 
of negative effect of the failure of his students in doing mathematics and attempt to encouraging by providing various scaffolding. Concerning this, the teacher from SHS 4 made less effort and her students made no improvement accordingly.

Refer to the work a student exhibited (Fig. 6b), it showed a different way of reasoning. Instead of multiplying the given with its additive inverse, he even multiplied it with the multiplicative inverse of $\sec ^{2}$ to get $\tan ^{2}$ in the frame of supplying the demand. Formally, one would directly multiply the demand to the given which will bring him to the solution. If it is the case, one possibly claim that he had used an algorithmic reasoning. However, the way he chose, could be classified as what Lithner [5] called creative mathematically founded reasoning and could be considered as formal expression [17].

\section{Students' perception on SB and SW}

The researchers equipped the students with the students book (SB) besides students worksheet (SW). The SB provides the students important and essential preliminaries knowledge on trigonometry. It intended to help the students working on the SW in a focus and directed way. It of course did not pretend to be a self-contained resource book. From Table 2, the students wished the SB gave more to support them fluently respond to the problems in the SW. Nevertheless, they witnessed the SB helped them to comprehend the materials more. Moreover, albeit difficult to pursuit, they asserted it endorsed to relating knowledge. In brief, the students perception told that the SB had played its role to make them easier to handle the tasks.

Whilst the SB achieved it mission, so did the SW. The students claimed the entire problem in the SW were difficult, but they believed they were capable to handle with the aids of expert others. Some of them even told the SW was interesting, forced them to more actively engaged, and enhancing their skill. The perception that the language the SW used was difficult to understand due to the unfamiliarity of the students. They rarely faced mathematics problems in such a way. Consequently, they hardly connected the information given in the problems to their prior knowledge to comprehend what the problem given and demanded. However, make the students familiar with problem solving needs longer duration of time and face them with it from their beginning days in school and doing it continuously.

\section{CONCLUSION}

The intervention effects on the students MRS, albeit the enhancement is low. However, the students enhancement on MRS of SHS 1 and SHS 2 outperformed the other two. Especially, those from SHS 1, they performed exceptional achievement. In Vygotsky's perspective, the students were capable activating their zone of proximal development through working together with advanced peers or expert adults. The students perceived that the SB had helped them to understand the materials more than ever. Moreover, albeit difficult to pursuit, they asserted it endorsed to relating knowledge. In brief, the students perception told that the SB had played its role to make them easier to handle the tasks. While concerning the SW, they got advantage of the experiences solving the problems in it. In some cases, they were able to transfer the knowledge and skills they grasped while solving the problems in the SW in-group to solving the problems in the post-test. 


\section{References}

National Council of Teachers of Mathematics. Principles and Standards of School Mathematics. 2000. Reston, VA: NCTM.

Artzt, A. F. and S. Yaloz-Femia. Mathematical Reasoning during Small-Group Problem Solving. In L.V. Stiff (Ed). Developing Mathematical Reasoning in Grade K-12. 1999. Reston,VA: NCTM.

Lithner, J. Mathematical reasoning in school tasks. Educational Studies in Mathematics. 2000.41(2), 165-190. doi.org/10.1023/A:1003956417456.

Norqvist, M. The effect of explanations on mathematical reasoning tasks. International Journal of Mathematical Education in Science and Technology. 2017. doi.org/10.1080/0020739X.2017.1340679.

Lithner, J. Principles for designing mathematical tasks that enhance imitative and creative reasoning. ZDM Mathematics Education. 2017. DOI 10.1007/s11858-017-0867-3.

Jalal, F., Samani, M, Chang, M. C., Stevenson, R., Bagatz, A. B. and Negara, S. D. Teacher Certification in Indonesia: A Strategy for Teacher Quality Improvement. 2009. Indonesia: Department Pendidikan Nasional Indonesia.

Napitupulu, E. E. On Developing Instruction Materials in Inculcating Secondary Students' Mathematical Reasoning Skills. Proceedings of the 2nd Annual International Seminar on Transformative Education and Educational Leadership. 2017 (a).

Saragih, S. \& Napitupulu, E. Developing Student-Centered Learning Model to Improve High Order Mathematical Thinking Ability. International Education Studies. 2015. 8(6), 104-112. doi:10.5539/ies. v8n6p104.

Napitupulu, E. E. Analyzing the Teaching and Learning of Mathematical Reasoning Skills in Secondary School. Asian Social Science. 2017(b). 13(12), 167-173. doi:10.5539/ass.v13n12p167.

Nieveen, N \& Folmer, E. Formative Evaluation in Educational Design Research. In Plomp, \& Nieveen (Eds.), Educational Design Research. 2013. Enschede: SLO.

Bergqvist, T. \& Lithner, J. Mathematical reasoning in teachers' presentations. Journal of Mathematical Behavior. 2012. 31, 252-269.

Bieda, K. N. Enacting Proof-Related Tasks in Middle School Mathematics: Challenges and Opportunities. Journal for Research in Mathematics Education. (2010). 41(4), 351-382. DOI: 10.2307/41103880.

Thiagarajan, S., Semmel, D. S. \& Semmel, M. Instructional Development for Training Teachers of Exceptional Children. A Sourse Book. 1974. Blomington: Central for Innovation on Teaching the Handicapped.

Hake, R. R. Interactive-Engagement versus Traditional Methods: A Six-Thousand-Student Survey of Mechanics Test Data for Introductory Physics Courses. Am. J. Phys. 1998. 66(1), 64-74.

Napitupulu, E. E. \& Minarni, A. Task-Driven: an Effort to Build Secondary Students Mathematical Reasoning Skills. Paper presented in Third Annual International Seminar on Transformative Education and Educational Leadership. 2018. Program Pascasarjana, Universitas Negeri Medan.

Burns, M., Pierson, E. \& Reddy, S. Working Together: How Teachers Teach and Students Learn in Collaborative Learning Environments. International Journal of Instruction. 2014. 7(1), 17-30.

Ayalon, M., Watson, A. \& Lerman, S. Reasoning about variables in 11 to 18 year olds: informal, schooled and formal expression in learning about functions. Math Ed Res J. (2016). 28(3), 379-404. DOI 10.1007/s13394-016-0171-5. 